\title{
Marketing Strategy through Markov Optimization to Predict Sales on Specific Periods
}

\author{
Husni Muharram Ritonga ${ }^{1}$, Andysah Putera Utama Siahaan ${ }^{2}$, Suginam ${ }^{3}$ \\ ${ }^{1}$ Faculty of Economics and Business, Universitas Pembangunan Panca Budi, Medan, Indonesia \\ ${ }^{2}$ Faculty of Computer Science, Universitas Pembangunan Panca Budi, Medan, Indonesia \\ ${ }^{3}$ Department of Computer Engineering, STMIK Budi Darma, Medan, Indonesia \\ ${ }^{2} \mathrm{Ph} . \mathrm{D}$. Student of School of Computer and Communication Engineering, Universiti Malaysia Perlis, Kangar, Malaysia \\ Email - andiesiahaan@gmail.com
}

\begin{abstract}
Competitive market competition so the company must be smart in managing finance. In promoting the selling point, marketing is the most important step to be considered. Promotional routine activity is one of the marketing techniques to increase consumer appeal to marketed products. One of the important agendas of promotion is the selection of the most appropriate promotional media. The problem that often occurs in the process of selecting a promotional media is the subjectivity of decision making. Marketing activities have a taxation fund that must be issued. Limited funds are one of the constraints of improving market strategy. So far, the selection of promotional media is performed by the company manually using standardized determination that already applies. It has many shortcomings, among others, regarding effectiveness and efficiency of time and limited funds. Markov Chain is very helpful to the company in analyzing the development of the company over a period. This method can predict the market share in the future so that company can optimize promotion cost at the certain time. Implementation of this algorithm produces a percentage of market share so that businesses can determine and choose which way is more appropriate to improve the company's market strategy. Assessment is done by looking at consumer criteria of a particular product. These criteria can determine consumer interest in a product so that it can be analyzed consumer behavior.
\end{abstract}

Key Words: Marketing, Strategy, Markov Chain, Product, company.

\section{INTRODUCTION:}

Improving strategy in marketing is not easy. It is a tough task of a marketing chief. The teams formed in improving quality and service are important to attract consumers to the products offered. Along with the development of competitors on the same product, each company has its way in conquering the world market. If it does not keep up with the market at that time, it will make the product unsold. Constraints on marketing is a financial problem faced by everyday companies [1]. In the economic field, there are many findings and business policies that can create its charm. This discovery encourages the emergence of business competitors to do the same for the smooth sale of their products. The producers face another problem on how to sell the product to the money that has been invested can immediately return to bring some benefits. To support all this is required a good marketing strategy. However, all that requires much money. Some actions are sometimes useless. The funds invested are large, but the yields are few and only payback. To survive or advance in marketing, this needs a good method.

Markov Chain is closely related to the theory of probability [5]. To provide a baseline analysis must first know the assumptions, definitions, up to several theorems required. The problem with business is how they keep their company in the future. Various businesses sell their products simultaneously [2]. Tight competition is a daily activity in the business world. Improving product quality can help consumers switch from one product to another, resulting in a decrease in market share. The author researches by using Markov Chain method to predict market share that aims to set the company's marketing strategy. This approach is expected to help the company in analyzing the products and consumers to get the benefits of the company.

\section{THEORIES:}

\subsection{Marketing}

Marketing is a way of selling products to consumers. It is performed to make that company owners get results from what they create. The exchange of goods to money is the result of that marketing. Marketing is the first step to profit. With targeted marketing techniques, this will create continuity between buyers and sellers. Marketing techniques need to be mastered to create a market strategy. It is an essential function for business actors to maintain the stability of the business world's surviva [3]. Marketing has a concept that is an activity undertaken to provide consumer appeal of a product. This concept varies according to the availability of goods and facilities that exist in a 
company. This concept must also be by the financial target that will be achieved from consumers. Putting the idea out of place will hamper the business world.

\subsection{Marketing Problem}

Companies must be able to survive in critical condition when faced with all the problems that exist and can win in the market competition. Marketing must be able to read market opportunities and produce performance and strategy and what customers need and desire. A business that successfully achieved its goals is strongly influenced by the intention and ability of the company in marketing its products. It is called the marketing function. This feature should be alert and responsive in finding opportunities that exist in meeting customer needs. Marketing is often regarded as one of the most common constraints in the development of business especially in the middle to lower business [4]. Business people must find the most appropriate way to anticipate marketing failures because any strategy error will have an impact on the company's earnings. Some of the following are the constraints faced in conducting marketing activities:

- The company does not pay attention to the techniques used in marketing planning. Direct marketing is done on the market without calculating the value of profit and loss. Imminent planning will render the product unsaleable.

- The market is not always fitting for all types of products. Companies must know and understand the type of market they will go. Companies must also know the ability of consumers in a particular market. If consumers can not afford, automated merchandise will not be sold.

- Competition is not always honest. Sometimes competition is spiked with threats from a competitor. The owner of the company should be able to anticipate this by improving marketing planning and outlining the most efficient strategy in the competitive environment.

- The selling price and purchase are not always fixed. All this depends on the changes that occur on demand and supply. There is no timeframe for when price fluctuations occur. It can happen when the product is plenty while the demand is small and the product is slight while the demand is increasing.

\subsection{Markov Chain}

Andrey A. Markov introduced the theory of Markov Chains in 1907. The Markov chain is linked to the brown movement and ergodic hypothesis, two important topics in physics in the early years of the 20th century, but it seems that Markov is more focused on extending scores of law in experiments -temperance. Markov Chain is a method that studies the properties of a current variable based on its past traits. It serves to obtain the properties of these variables in the future [6][7]. This model corresponds to a series of processes in which the incidence of an experiment depends only on the next event preceding it and is independent of the previous sequence of events.

This method is first used to analyze and estimate the behavior of gas particles in a closed container and forecast weather conditions. The Markov process has been widely applied to analyze the movement of interest in an object so that it is often used to analyze marketing techniques [8]. The goal is for business people to know the constraints of what happens and predictions of the future of his company.

\section{RESULT AND DISCUSSION:}

This trial will involve an example of a strategy in car sales. Data and car brands are taken as fictitious examples; Not based on the original data of a company. Here will be attached five car brands with each user number and percentage of use. The number of users is taken based on the fictional numbers as well as the experimental material. There are 300 respondents who serve as initial data to solve the problem. Table 1 is a list of cars used as experimental materials.

Table 1. Intial data

\begin{tabular}{|c|l|c|c|}
\hline No. & \multicolumn{1}{|c|}{ Name } & Usage & Proportion \\
\hline 1 & Toyota & 88 & 0,29 \\
\hline 2 & Daihatsu & 78 & 0,25 \\
\hline 3 & Suzuki & 65 & 0,21 \\
\hline 4 & Mercedez & 45 & 0,15 \\
\hline 5 & BMW & 30 & 0,10 \\
\hline
\end{tabular}

There are as many as 5 criteria that become the benchmark of this marketing. These criteria are:

$$
\mathrm{C} 1=\text { Comfort }
$$




$$
\begin{array}{ll}
\mathrm{C} 2 & =\text { Practice } \\
\mathrm{C} 3 & =\text { Price } \\
\mathrm{C} 4 & =\text { Quality } \\
\mathrm{C} 5 & =\text { Design }
\end{array}
$$

Table 2 describes the distribution of answers from respondents based on listed criteria. 300 people are willing to be respondents to run the process of market share analysis. There are five brands of cars that are in comparison with five criteria. Each respondent will choose which brand that is suited to himself. For example, Toyota gets 88 respondents with C1 (Comfort) criteria $=15, \mathrm{C} 2($ Practice $)=24, \mathrm{C} 3($ Price $)=19, \mathrm{C} 4($ Quality $)=16$ and C5 $($ Design $)=$ 14.

Table 2. Respondents data

\begin{tabular}{|c|l|c|c|c|c|c|c|}
\hline No. & Name & C1 & C2 & C3 & C4 & C5 & Total \\
\hline 1 & Toyota & 15 & 24 & 19 & 16 & 14 & 88 \\
\hline 2 & Daihatsu & 15 & 20 & 12 & 16 & 14 & 77 \\
\hline 3 & Suzuki & 16 & 15 & 11 & 13 & 10 & 65 \\
\hline 4 & Mercedez & 10 & 7 & 4 & 9 & 10 & 40 \\
\hline 5 & BMW & 8 & 5 & 4 & 6 & 7 & 30 \\
\hline
\end{tabular}

Based on the displacement data collected over the course of a period, each car company gets acquisitions from other brands. Table 3 is a data transfer performed by other brands against existing car brands. For example, Toyota gets 19 consumers consisting of six from Daihatsu, eight from Suzuki, three from Mercedez and two from BMW while the other four brands get consumers from others as well. These movements are mutually done with certain motives.

Table 3. Customer acquisition data for one period

\begin{tabular}{|c|l|c|c|c|c|c|c|}
\hline No. & Name & To & Da & Su & Me & Bm & Acq. \\
\hline 1 & Toyota & 0 & 6 & 8 & 3 & 2 & $\mathbf{1 9}$ \\
\hline 2 & Daihatsu & 7 & 0 & 7 & 1 & 1 & $\mathbf{1 6}$ \\
\hline 3 & Suzuki & 2 & 2 & 0 & 3 & 2 & $\mathbf{9}$ \\
\hline 4 & Mercedez & 2 & 4 & 1 & 0 & 3 & $\mathbf{1 0}$ \\
\hline 5 & BMW & 1 & 2 & 1 & 1 & 0 & $\mathbf{5}$ \\
\hline \multirow{2}{*}{} & Loss & $\mathbf{1 2}$ & $\mathbf{1 4}$ & $\mathbf{1 7}$ & $\mathbf{8}$ & $\mathbf{8}$ & \multicolumn{1}{|c}{} \\
\cline { 2 - 6 } & & & \multicolumn{1}{|c}{}
\end{tabular}

In addition to the acquisition, losses are also obtained by each company. A transition is a disadvantage to the company. Table 4 illustrates the consumer loss data obtained by each company. For example, Toyota lost 12 consumers consisting of seven moved to Daihatsu, two moved to Suzuki, two moved to Mercedez, and one moved to BMW while the other four brands earn losses with varying amounts.

Table 4. Customer loss data on various car brands

\begin{tabular}{|c|l|c|c|c|c|c|c|}
\hline No. & Name & To & Da & Su & Me & Bm & Loss \\
\hline 1 & Toyota & 0 & 7 & 2 & 2 & 1 & $\mathbf{1 2}$ \\
\hline 2 & Daihatsu & 6 & 0 & 2 & 4 & 2 & $\mathbf{1 4}$ \\
\hline 3 & Suzuki & 8 & 7 & 0 & 1 & 1 & $\mathbf{1 7}$ \\
\hline 4 & Mercedez & 3 & 1 & 3 & 0 & 1 & $\mathbf{8}$ \\
\hline 5 & BMW & 2 & 1 & 2 & 3 & 0 & $\mathbf{8}$ \\
\hline \multirow{2}{*}{} & Acq. & $\mathbf{1 9}$ & $\mathbf{1 6}$ & $\mathbf{9}$ & $\mathbf{1 0}$ & $\mathbf{5}$ & \multicolumn{1}{|c}{} \\
\cline { 2 - 5 } & & & \multicolumn{1}{|c}{}
\end{tabular}

Table 5 is the result of the acquisition and loss of consumers for each car company over a period. $\mathrm{B}=$ before where this is the beginning of periode while $\mathrm{N}=\mathrm{New}$ where this is the next period or the end of the earlier period. Toyota achieved an increase over the previous period. It gets 19 new acquisitions and 12 consumer losses, resulting in an increase in purchases by seven consumers. Daihatsu has an increase in two consumers, Suzuki has decreased eight consumers, Mercedez gets two consumers, and BMW has decreased by three consumers. 
Table 5. Brand transition for one period

\begin{tabular}{|c|l|c|c|c|c|}
\hline No. & Name & B & Ac & Lo & N \\
\hline 1 & Toyota & 88 & 19 & 12 & 95 \\
\hline 2 & Daihatsu & 77 & 16 & 14 & 79 \\
\hline 3 & Suzuki & 65 & 9 & 17 & 57 \\
\hline 4 & Mercedez & 40 & 10 & 8 & 42 \\
\hline 5 & BMW & 30 & 5 & 8 & 27 \\
\hline
\end{tabular}

Table 6 states that not all consumers in the past period did the brand shifting, some among those who did not make a move. There are as many as 241 that still remain in the old company, Toyota $=76$, Daihatsu $=63$, Suzuki $=$ 48 , Mercedes $=32$, and BMW $=22$.

Table 6. Brand transition data

\begin{tabular}{|c|l|c|c|c|c|c|c|}
\hline No. & Name & To & Da & Su & Me & Bm & Rb \\
\hline 1 & Toyota & $\mathbf{7 6}$ & 7 & 2 & 2 & 1 & $\mathbf{8 8}$ \\
\hline 2 & Daihatsu & 6 & $\mathbf{6 3}$ & 2 & 4 & 2 & $\mathbf{7 7}$ \\
\hline 3 & Suzuki & 8 & 7 & $\mathbf{4 8}$ & 1 & 1 & $\mathbf{6 5}$ \\
\hline 4 & Mercedez & 3 & 1 & 3 & $\mathbf{3 2}$ & 1 & $\mathbf{4 0}$ \\
\hline 5 & BMW & 2 & 1 & 2 & 3 & $\mathbf{2 2}$ & $\mathbf{3 0}$ \\
\hline & Rn & $\mathbf{9 5}$ & $\mathbf{7 9}$ & $\mathbf{5 7}$ & $\mathbf{4 2}$ & $\mathbf{2 7}$ & $\mathbf{3 0 0}$ \\
\hline
\end{tabular}

$$
\begin{aligned}
\text { Toyota } & =\frac{76}{88} * 100 \% \\
& =86.36 \% \\
\text { Daihatsu } & =\frac{63}{77} * 100 \% \\
& =81.81 \% \\
\text { Suzuki } & =\frac{48}{65} * 100 \% \\
& =73.85 \% \\
\text { Mercedez } & =\frac{32}{40} * 100 \% \\
& =80.00 \% \\
\text { BMW } & =\frac{22}{30} * 100 \% \\
& =73.33 \%
\end{aligned}
$$

The following percentage calculation results explain some companies lose the market share, and some just get it. Suzuki (-14.03\%) and BMW (-11.11\%) have decreased in the next period. Toyota (7.37\%), Daihatsu (2.53\%), and Mercedez (4.76\%) have increased in the new period.

$$
\begin{aligned}
\text { Toyota } & =\frac{95-88}{95} * 100 \% \\
& =7.37 \% \\
\text { Daihatsu } & =\frac{79-77}{79} * 100 \% \\
& =2.53 \% \\
\text { Suzuki } & =\frac{57-65}{57} * 100 \% \\
& =-14.03 \% \\
\text { Mercedez } & =\frac{42-40}{42} * 100 \% \\
& =4.76 \%
\end{aligned}
$$




$$
\begin{aligned}
\mathrm{BMW} & =\frac{27-30}{27} * 100 \% \\
& =-11.11 \%
\end{aligned}
$$

The calculation of market share can be done after the data acquisition and loss are met well. There are three periods as the comparative material of the market share. There are three variables in this calculation, MS1 = market share period one, MS2 = market share period two, and MS3 = market share period three. The calculation of the matrix to obtain market share can be seen as follows.

$$
D=\left[\begin{array}{ccccc}
76 & 7 & 2 & 2 & 1 \\
6 & 63 & 2 & 4 & 2 \\
8 & 7 & 48 & 1 & 1 \\
3 & 1 & 3 & 32 & 1 \\
2 & 1 & 2 & 3 & 22
\end{array}\right] R b=\left[\begin{array}{l}
88 \\
77 \\
65 \\
40 \\
30
\end{array}\right]
$$

The following formula is used to find the transition probabilities.

$$
T P(\text { col, row })=\frac{D(\text { col }, \text { row })}{R b(\text { row })}
$$

$$
\begin{aligned}
\operatorname{TP}_{(1,1)} & =\frac{D(1,1)}{R b(1)} \\
& =\frac{76}{88} \\
& =0.86 \\
& =\frac{D(1,2)}{R b(2)} \\
& =\frac{6}{77} \\
& =0.08 \\
\operatorname{TP}_{(2,1)} & =\frac{D(1,3)}{R b(3)} \\
& =\frac{8}{65} \\
& =0.12 \\
\operatorname{TP}_{(3,1)} & =\frac{D(1,4)}{R b(4)} \\
& =\frac{3}{40} \\
& =0.08 \\
\operatorname{TP}_{(4,1)} & =\frac{D(1,5)}{R b(5)} \\
& =\frac{2}{30} \\
& =0.07
\end{aligned}
$$

$$
T P=\left[\begin{array}{ccccc}
0.86 & 0.08 & 0.12 & 0.08 & 0.07 \\
0.08 & 0.82 & 0.11 & 0.03 & 0.03 \\
0.02 & 0.03 & 0.74 & 0.08 & 0.07 \\
0.02 & 0.05 & 0.02 & 0.8 & 0.1 \\
0.01 & 0.03 & 0.02 & 0.03 & 0.73
\end{array}\right]
$$

This calculation starts with $\mathrm{M}_{(1,1)}$ to $\mathrm{M}_{(5,5)}$. The result obtained is the transition probability (TP) of company at a given period as seen in earlier matrix.

$$
M S 1=\left[\begin{array}{l}
0.29 \\
0.26 \\
0.22 \\
0.14 \\
0.10
\end{array}\right]
$$




$$
\begin{aligned}
& M S 2=\left[\begin{array}{ccccc}
0.86 & 0.08 & 0.12 & 0.08 & 0.07 \\
0.08 & 0.82 & 0.11 & 0.03 & 0.03 \\
0.02 & 0.03 & 0.74 & 0.08 & 0.07 \\
0.02 & 0.05 & 0.02 & 0.8 & 0.1 \\
0.01 & 0.03 & 0.02 & 0.03 & 0.73
\end{array}\right] *\left[\begin{array}{c}
0.29 \\
0.26 \\
0.22 \\
0.13 \\
0.10
\end{array}\right] \\
& M S 2=\left[\begin{array}{l}
0.32 \\
0.26 \\
0.19 \\
0.14 \\
0.09
\end{array}\right] \\
& M S 3=\left[\begin{array}{ccccc}
0.86 & 0.08 & 0.12 & 0.08 & 0.07 \\
0.08 & 0.82 & 0.11 & 0.03 & 0.03 \\
0.02 & 0.03 & 0.74 & 0.08 & 0.07 \\
0.02 & 0.05 & 0.02 & 0.8 & 0.1 \\
0.01 & 0.03 & 0.02 & 0.03 & 0.73
\end{array}\right] *\left[\begin{array}{c}
0.32 \\
0.26 \\
0.19 \\
0.14 \\
0.09
\end{array}\right] \\
& M S 3=\left[\begin{array}{c}
0.33 \\
0.27 \\
0.17 \\
0.14 \\
0.08
\end{array}\right]
\end{aligned}
$$

Table 7. Comparison of market share value in three periods

\begin{tabular}{|l|c|c|c|}
\hline \multicolumn{1}{|c|}{ Name } & MS1 & MS2 & MS3 \\
\hline Toyota & 0,29 & 0,32 & 0,33 \\
\hline Daihatsu & 0,26 & 0,26 & 0,27 \\
\hline Suzuki & 0,22 & 0,19 & 0,17 \\
\hline Mercedez & 0,13 & 0,14 & 0,14 \\
\hline BMW & 0,10 & 0,09 & 0,08 \\
\hline
\end{tabular}

Table 7 describes the comparisons of market share calculations in three periods. Market share calculations show that in all three periods Toyota has increased consumer. Daihatsu also gets the same acquisition, while Suzuki and BMW decreased in the second and third periods. Mercedes gained a gain of 0.01 in the second period. In the third period, it did not increase or decrease. Markov Chain results can be used to analyze marketing techniques undertaken company. A company can think of the next strategies based on the customer's acquisition estimation. Although these results are not necessarily accurate, this can at least be a motivation for developing future promotional techniques.

\section{CONCLUSION:}

A marketing strategy is needed to maintain or increase sales. There is much fierce competition in the business world. Market share prediction is the important thing to do to determine the direction and purpose of the company. Markov method is very suitable to predict the performance results of the company based on data obtained in a given period. However, the prediction method also has weaknesses. Markov chain analysis is hard to approach the reality because of the requirements for constant transition probabilities over time while within a period of data may vary according to actual conditions. This method only helps to describe predictions over the coming periods; It can not take the decisions that happen in the real company.

\section{REFERENCES:}

1. T. Lishchenko, M.-D. Shieh and K.-H. Chen, "International Marketing Strategy of Design-Driven Companies," in International Conference on Financial Management and Economics, Singapore, 2011.

2. S. Zou, "Standardization of International Marketing Strategy by Firms from a Developing Country," International Marketing Review, vol. 14, no. 2, pp. 107-123, 1997.

3. S. Schwarzl and M. Grabowska, "Online Marketing Strategies: the Future is Here," Journal of International Studies, vol. 8, no. 2, pp. 187-196, 2015. 
4. Rusiadi, A. Novalina, P. Khairani and A. P. U. Siahaan, "Indonesia Macro Economy Stability Pattern Prediction (Mundell-Flamming Model)," IOSR Journal of Economics and Finance, vol. 7, no. 5, pp. 16-23, 2016.

5. G. Padma and C. Vijayalakshmi, "An Analysis of Continuous Time Markov Chains using Generator Matrices," International Journal of Computer Applications, vol. 35, no. 10, pp. 20-24, 2011.

6. P. C. Doerschuk, R. R. Tenney and A. S. Willsky, "Modelling Electrocardiograms Using Interacting Markov Chains," International Journal of Systems Science, vol. 21, no. 2, pp. 257-283, 1990.

7. Q.-x. Zhou, "Application of Weighted Markov Chain in Stock Price Forecasting of China Sport Industry," International Journal of u- and e- Service, Science and Technology, vol. 8, no. 2, pp. 219-226, 2015.

8. T. Liu and A. Hohmann, "Applying the Markov Chain theory to Analyze the Attacking Actions between FC Barcelona and Manchester United in the European Champions League Final," International Journal of Sports Science and Engineering, vol. 7, no. 2, pp. 72-86, 2013. 